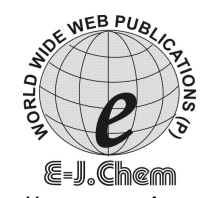

http://www.e-journals.net

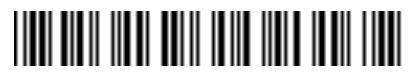

ISSN: 0973-4945; CODEN ECJHAO

E-Journal of Chemistry

Vol. 4, No. 4, pp. 546-549, October 2007

\title{
Isolation and Identification of Anthralin From the Roots of Rhubarb Plant (Rheum palmatum)
}

\author{
A. ASHNAGAR, * N. GHARIB NASERI, ${ }^{*}$ and H. HAIDARI NASAB \\ School of Pharmacy, Ahwaz Jundi Shapour Univ. of Medical Sciences, Ahwaz, Iran. \\ \#Ahwaz Faculty of Petroleum Engineering, Petroleum Univ. of Technology, Iran. \\ aashnagar2003@yahoo.com
}

Received 4 March 2007; Accepted 30 March 2007

\begin{abstract}
Anthralin is medically and chemically an important compound which can be found in rhubarb roots. Anthralin and anthralin derivatives have been used as antipsoriatic drugs. In this research, pure anthralin was isolated from the rhubarb roots by maceration and Soxhlet extraction methods in various polar and non-polar solvents. Successive TLC and column chromatography on silica gel with chloroform as the mobile phase afforded two distinct fractions with $\mathrm{R}_{\mathrm{f}}=0.54$ and 0.61 . The ${ }^{1} \mathrm{HNMR},{ }^{13} \mathrm{CNMR}, \mathrm{IR}, \mathrm{UV}$ and MS spectra showed that the fraction with $R_{f}=0.61$ was anthralin. In both methods, methanol was found to be the most suitable solvent for extraction.
\end{abstract}

Keywords: Rhubarb, Anthralin, 1,8-Dihydroxy-9-anthrone, Rheum palmatum

\section{Introduction}

Rhubarb is a perennial plant that grows from thick short rhizomes, comprising the genus Rheum. The plant is indigenous to Asia. Varieties of rhubarb have a long history as medicinal plants in traditional Chinese medicine, but the use of rhubarb as food is a relatively recent innovation, first recorded in $17^{\text {th }}$ century England, after affordable sugar became available to common people [Scientific classification: Kingdom; Plantae : Division; Magnoliophyta: Class; Magnoliopsida : Order; Caryophyllales: Family; Polygonaceae: Genus; Rheum L.]. Rhubarb is now grown in many areas, primarily for its fleshy petioles, commonly known as rhubarb sticks. In temperate climates rhubarb is one of the first food plants to be ready for harvest, usually in mid to late spring (April/May in the Northern Hemisphere, October/November in the Southern). The petioles can be cooked in a variety of ways. Rhubarb is used as a strong laxative and for its astringent effect on the mucous 
membranes of the mouth and the nasal cavity. The roots and stems are rich in anthraquinones, such as emodin (1,3,8-trihydroxy-6-methyl-9,10-anthraquinone) and rhein. These substances are cathartic and laxative, which explains the sporadic abuse of Rhubarb as a slimming agent. Anthraquinones are yellow or orange and may colour the urine ${ }^{1}$. Rhubarb root has properties that make it a highly effective laxative. Its astringent qualities help to improve bowel tone after it has purged the intestines, making it an excellent agent for improving the tone and health of the digestive tract. Its laxative effects make it a valuable aid in the treatment of chronic constipation, hemorrhoids, and gastroenteritis. Skin eruptions caused by problems in elimination are also treated with rhubarb root. The Western rhubarb root, being milder, is used in treating infant digestive problems, constipation, or diarrhea ${ }^{2}$. Rhubarb root has been found useful in controlling gastrointestinal hemorrhage by promoting the formation of blood platelets. This increase in the number of platelets shortens blood clotting time and is helpful in treating jaundice. Recent studies in China and Japan demonstrated that rhubarb root can delay or stop the progression of chronic renal failure. One of the tannin components of rhubarb root, lindleyin, has been shown to act as an antiinflammatory agent with fever-reducing properties similar to those of aspirin. Emodin, another component of Chinese rhubarb root, has been found to inhibit the growth of cancer cells. Chinese herbalists also use rhubarb root for diseases and disorders in the upper body, including sinus and lung infections, nose bleeding, and eye infections. According to the principles of traditional Chinese medicine, rhubarb root makes the heat in the upper body discharge through the bowel ${ }^{3}$.

\section{Experimental}

NMR spectra were recorded on Varian FT-NMR spectrophtometer $400 \mathrm{MHz}\left({ }^{1} \mathrm{H}\right)$ and 100 $\mathrm{MHz}\left({ }^{13} \mathrm{C}\right)$ using TMS as internal standard. Mass spectra were measured on a QP-1000 Shimadzu (Japan) mass spectrometer. Infra-red spectra were recorded using a JASCO, IR700 Infrared spectrophotometer. UV-Visible spectra were recorded using a JASCO, 810UV spectrophotometer. All the chemicals were purchased from Merck.

\section{Supplying the rhubarb roots}

Five kilograms of the dried rhubarb roots were purchased from Isfahan Goldarou Company. The plant was identified as Rheum palmatum by the faculties of agriculture and sciences of Shahid Chamran University, Ahwaz, Iran and by Isfahan Goldarou Company. The roots of the plant were crushed then ground to the desired particle size by an electrical mill.

\section{Extraction of the dried ground roots by maceration method}

Maceration of $150 \mathrm{~g}$ of the dried roots in $350 \mathrm{~mL}$ of each of the individual polar and nonpolar solvents (methylene chloride, benzene, toluene, acetone, chloroform and methanol) was carried out. The mixture was shaken by an electrical shaker at room temperature for $48 \mathrm{~h}$. After that time, the mixture was filtered and the solvent was removed on a rotary evaporator. After drying the residue at $70{ }^{\circ} \mathrm{C}$ in an electrical oven, a yellow powder was obtained. The results are given in Table 1.

\section{Soxhlet extraction of the dried ground roots}

Soxhlet extraction of $25 \mathrm{~g}$ of the dried ground roots in $300 \mathrm{~mL}$ of each of the individual polar and non-polar solvents (methylene chloride, benzene, toluene, acetone, chloroform and methanol) for $8 \mathrm{~h}$ followed by removal of the solvent on rotary evaporator gave a yellow 
solid material. The process was repeated several times to obtain sufficient material. The results are given in Table 1 .

Table 1. Results obtained from the extraction of the ground Rhubarb roots

\begin{tabular}{lcccccc}
\hline No. & $\begin{array}{c}\text { Method of } \\
\text { extraction }\end{array}$ & $\begin{array}{c}\text { Ground } \\
\text { roots used } \\
g\end{array}$ & $\begin{array}{c}\text { Solvent } \\
\text { used }\end{array}$ & $\begin{array}{c}\text { Extraction } \\
\text { time } \\
h\end{array}$ & $\begin{array}{c}\text { Crude } \\
\text { extract } \\
g\end{array}$ & $\begin{array}{c}\text { Yield } \\
\%\end{array}$ \\
\hline 1 & Soxhlet & 150 & Methanol & 8 & 7.3 & 4.87 \\
2 & Soxhlet & 150 & Benzene & 8 & 2.3 & 1.53 \\
3 & Soxhlet & 150 & Toluene & 8 & 4.4 & 2.93 \\
4 & Soxhlet & 150 & $\mathrm{CHCl}_{3}$ & 8 & 3.2 & 2.13 \\
5 & Soxhlet & 150 & $\mathrm{CH}_{2} \mathrm{Cl}_{2}$ & 8 & 4.1 & 2.73 \\
6 & Soxhlet & 150 & $\mathrm{Acetone}$ & 8 & 2.1 & 1.4 \\
7 & Maceration & 150 & $\mathrm{Methanol}^{2}$ & 48 & 6.2 & 4.13 \\
8 & Maceration & 150 & $\mathrm{Benzene}$ & 48 & 2.0 & 1.33 \\
9 & Maceration & 150 & Toluene & 48 & 3.7 & 2.47 \\
10 & Maceration & 150 & $\mathrm{CHCl}_{3}$ & 48 & 2.7 & 1.8 \\
11 & Maceration & 150 & $\mathrm{CH}_{2} \mathrm{Cl}_{2}$ & 48 & 3.9 & 2.6 \\
12 & Maceration & 150 & $\mathrm{Acetone}^{2}$ & 48 & 2.0 & 1.33 \\
\hline
\end{tabular}

Thin Layer Chromatography analysis of the extracted solid material

TLC on silica gel with chloroform as the mobile phase was carried out. The results showed two distinct coloured spots with $\mathrm{R}_{\mathrm{f}}=0.54$, and 0.61 .

Column chromatography analysis of the extracted solid material

$1 \mathrm{~g}$ of the solid extract was dissolved in $3 \mathrm{~mL}$ of chloroform and then column chromatographed on silica gel (60 mesh) with chloroform as the mobile phase. Two distinct coloured fractions with $\mathrm{R}_{\mathrm{f}}=0.54$, and 0.61 were collected. Finally one major fraction with $\mathrm{R}_{\mathrm{f}}=0.61$ was separated and characterized. IR, UV-Visible, ${ }^{1} \mathrm{HNMR},{ }^{13} \mathrm{CNMR}$, and MS spectra of the fraction was taken. This process was repeated several times and the fractions with $\mathrm{R}_{\mathrm{f}}=0.61$ were added together.

Characterization of the component with $R_{f}=0.61$

IR (mull in Nujol) showed $\bar{v}\left(\mathrm{~cm}^{-1}\right): 2922,2854(\mathrm{CH}, \mathrm{s}), 1613(\mathrm{C}=\mathrm{O}, \mathrm{s}), 1596,1480,1460$ $\left(\mathrm{C}=\mathrm{C}\right.$ aromatic, s), 1274, $1219(\mathrm{C}-\mathrm{O}, \mathrm{s}), 773,722\left(\mathrm{CH}_{\text {oop }}\right.$, aromatic, s); UV spectrum in chloroform showed $\lambda_{\max }=356.5,287.5,256.5,237$, and $230 \mathrm{~nm} ;{ }^{1} \mathrm{HNMR}\left(\mathrm{CDCl}_{3}, 400\right.$ $\mathrm{MHz})$ had $\delta(\mathrm{ppm}): 4.18$ (s,CH2), $6.75-6.79$ (d, H-2+H-7+H-4+H-5), 7.34-7.37 (t,H-3+ H6), $12.13(\mathrm{~s}, 2 \times \mathrm{OH})$; its ${ }^{13} \mathrm{CNMR}\left(\mathrm{CDCl}_{3}, 100 \mathrm{MHz}\right)$ had $\delta(\mathrm{ppm}): 115.4(\mathrm{C}-4 / \mathrm{C}-5), 115.7$ (C-5/C-4), 118.6 (C-3/C-6), 119.5 (C-6/C-3), 135.6 (C-2/C-7), 136.1 (C-7/C-2), 161.9 (C1/C-8), 162.8 (C-8/C-1), $193.9(\mathrm{C}=\mathrm{O}) ; \mathrm{MS}(\mathrm{EI})$ showed m/z: $227\left[(\mathrm{M}+\mathrm{H})^{+}, 26.8 \%\right], 226$ $\left[\mathrm{M}^{+}, 100 \%\right], 210\left[(\mathrm{M}-\mathrm{CH} 2)^{+.}, 4.87 \%\right], 198\left[(\mathrm{M}-\mathrm{CO})^{+}, 19.5 \%\right], 182\left[(210-\mathrm{CO})^{+.}\right.$, $2.43 \%$ ]. The m.p. is $181{ }^{\circ} \mathrm{C}$ (literature; m.p. $180-182^{\circ} \mathrm{C}$ ). On the basis of these results, this fraction was identified as 1,8-dihydroxy-9-anthrone, Anthralin.

\section{Results and Discussion}

Rhubarb is the root of different species of Rheum plant and available commercially under various names, but the geographical source of all the species are same. Chinese or Turkish 
rhubarb available commercially in brownish-yellow pieces of various sizes. The preparations used in medicine are: the powdered root, a fluid extract, a tincture, syrup, infusion and solution. The chemical constituents of rhubarb root not yet completely known. Recent investigations indicate that the most important constituents are number of substances which may be divided into two groups: tannoid constituents which are astringent, nd purgative constituents which are laxative. Several of these groups have been isolated in a free state. Anthralin was first synthesized in 1916 and since then, anthralin and its various derivatives have been used extensively as an antipsoriatic drugs ${ }^{4,5}$. Regarding the medicinal and chemical importance of anthralin, it was decided to carry out the following objectives in this research: (i) isolation of anthralin from the rhubarb roots by maceration and Soxhlet extraction methods using various polar and non-polar solvents and finally (ii) confirmation of the chemical structure of anthralin by various spectroscopic methods. The plant was identified as Rheum palmatum. Maceration of the powered roots in various polar and nonpolar solvents (methylene chloride, benzene, toluene, acetone, chloroform and methanol) were carried out at room temperature for $48 \mathrm{~h}$. The best solvent was found to be methanol (Table 1). Soxhlet extraction of the powdered roots was carried out in the same solvents mentioned above for $8 \mathrm{~h}$. In this method too, the best solvent was found to be methanol (Table 1). However, the yield from Soxhlet extraction method was higher than that from the maceration method in the same solvent $(4.87 \%$ and $4.13 \%$, respectively) and the isolation time was much shorter ( $8 \mathrm{~h}$ versus $48 \mathrm{~h}$ ) as well. Successive TLC and column chromatography of the extracted yellow solid material resulted in the separation of two fractions with $R_{f}=0.54$, and 0.61 with the last one as the major fraction. IR, UV-Visible, ${ }^{1} \mathrm{HNMR},{ }^{13} \mathrm{CNMR}$, and MS spectra of the fraction with $\mathrm{R}_{\mathrm{f}}=0.61$ were taken. It had m.p. $181^{\circ} \mathrm{C}$ (literature $189-182^{\circ} \mathrm{C}$ ). The IR and UV spectra were compared with the corresponding standard spectra, they were almost identical. On the basis of the spectroscopic results and melting point, it was confirmed that the fraction with $R_{f}=0.61$ was pure anthralin.

\section{References}

1. http://en.wikipedia.org/wiki/Rhubarb; Accessed on $20^{\text {th }}$ of Feb. 2007.

2. http://www.findarticles.com/p/articles/mi_g2603/is_0006/ai_2603000630

3. http://www.findarticles.com/p/articles/mi_g2603/is_0006/ai_2603000630; Accessed on $20^{\text {th }}$ Feb. 2007.

4. Ashton RE, Lowe NJ, and Whitefield M, American Academy of Dermatology, 1983, 9 (2), 173-192.

5. Gharib Naseri N, Ashnagar A, and Bruce JM, Asian J.Chem., 2005, 17 (4), 21522158. 


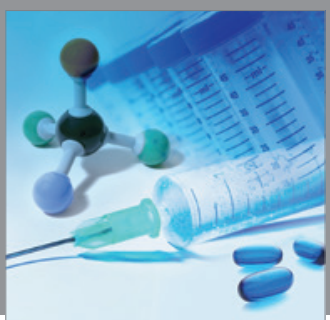

International Journal of

Medicinal Chemistry

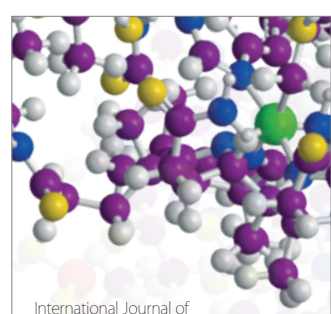

Carbohydrate Chemistry

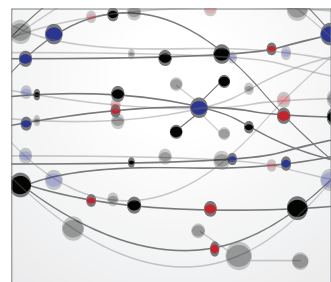

The Scientific World Journal
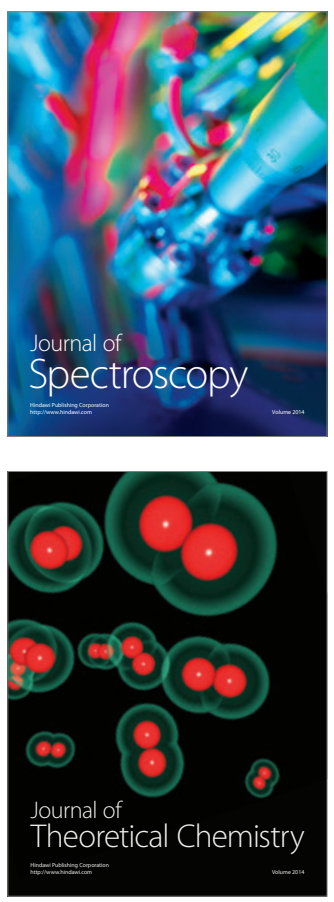
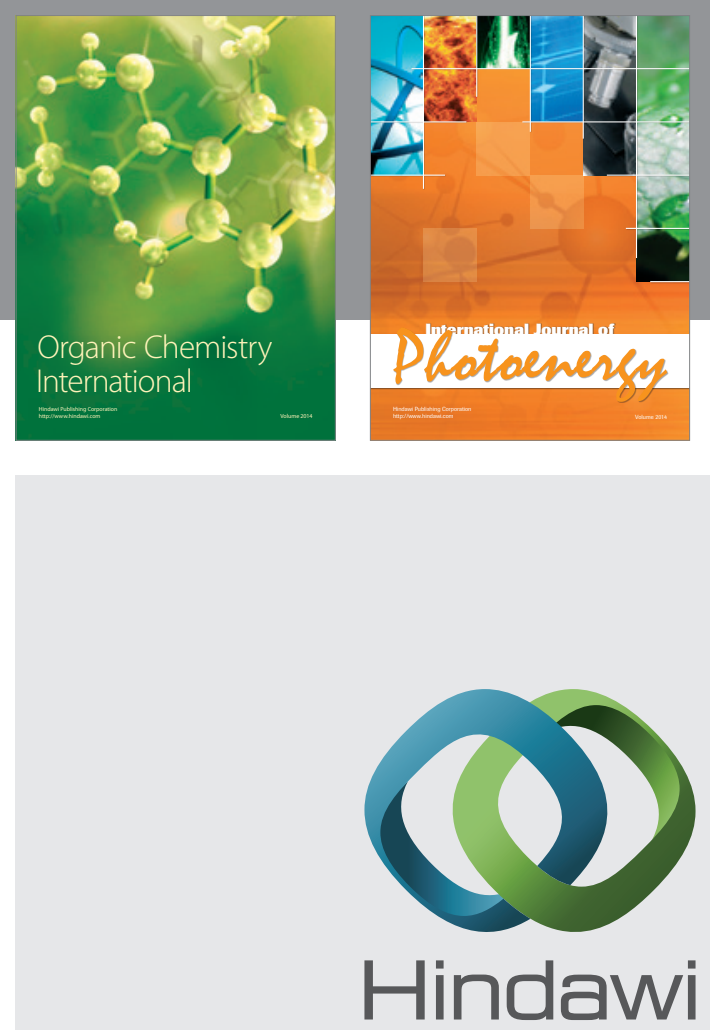

Submit your manuscripts at

http://www.hindawi.com
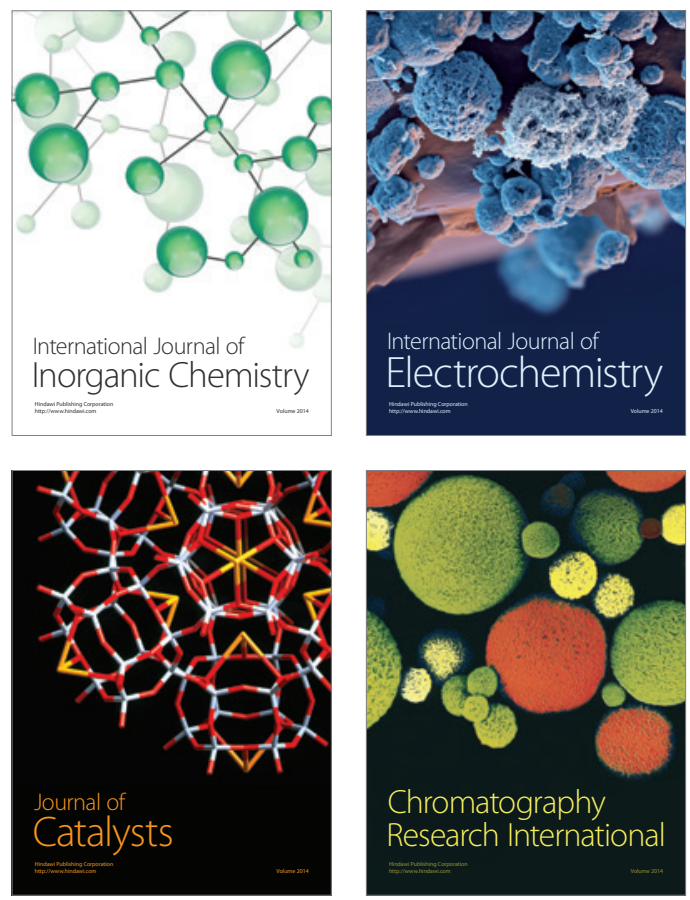
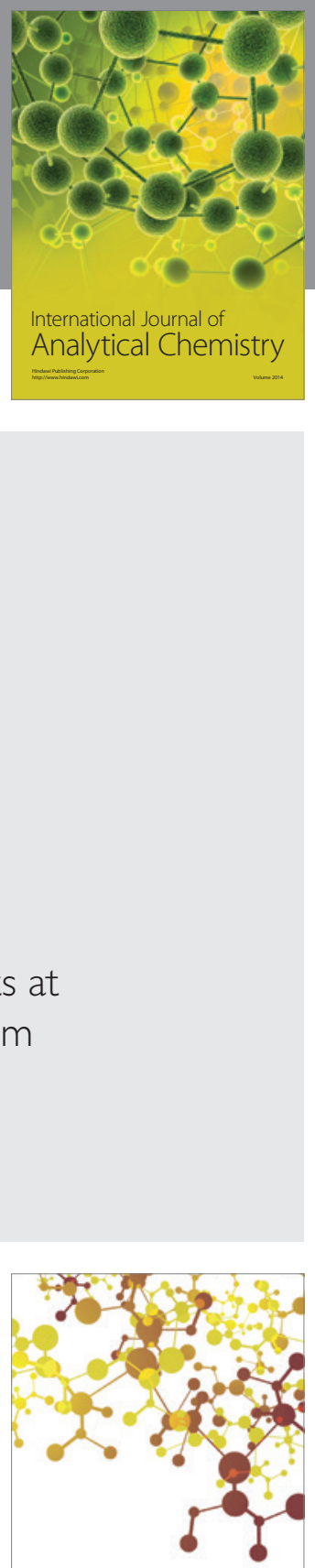

Journal of

Applied Chemistry
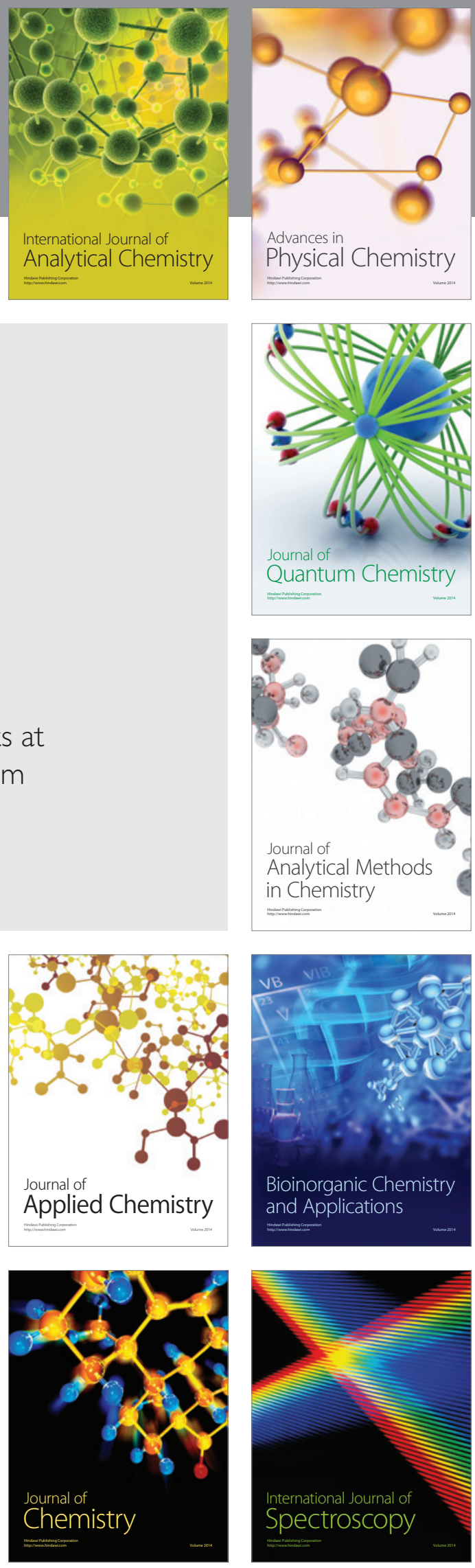